\title{
PLACES: A Framework for Supporting Blind and Partially Sighted People in Outdoor Leisure Activities
}

\author{
Maryam Bandukda \\ UCL Interaction Centre, Global Disability Innovation Hub, m.bandukda@ucl.ac.uk \\ Catherine Holloway \\ UCL Interaction Centre, Global Disability Innovation Hub, c.holloway@ucl.ac.uk
}

Aneesha Singh

UCL Interaction Centre, aneesha.singh@ucl.ac.uk

Nadia Berthouze

UCL Interaction Centre, n.berthouze@ucl.ac.uk

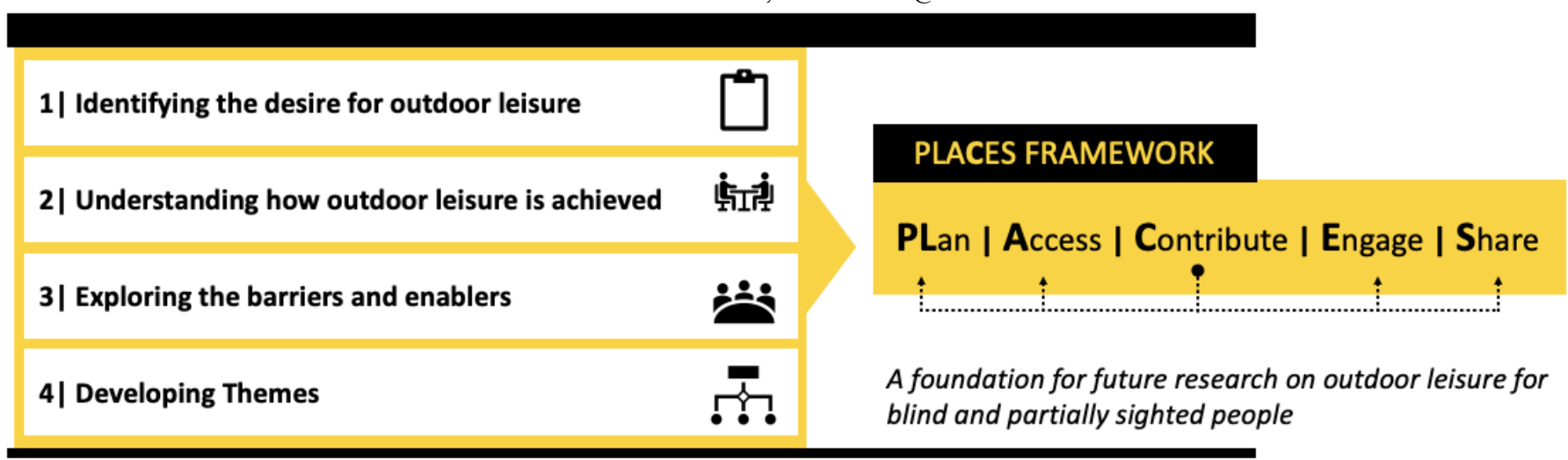

Figure 1 The PLACES framework

\begin{abstract}
Interacting with natural environments such as parks and the countryside improves health and wellbeing. These spaces allow for exercise, relaxation, socialising and exploring nature, however, they are often not used by blind and partially sighted people (BPSP). To better understand the needs of BPSP for outdoor leisure experience and barriers encountered in planning, accessing and engaging with natural environments, we conducted an exploratory qualitative online survey (22 BPSP), semi-structured interviews (20 BPSP) and a focus group (9 BPSP; 1 support worker). We also explored how current technologies support park experiences for BPSP. Our findings identify common barriers across the stages of planning (e.g. limited accessible information about parks), accessing (e.g. poor wayfinding systems), engaging with and sharing leisure experiences. Across all stages (PLan, Access, Engage, Share) we found a common theme of Contribute. BPSP wished to co-plan their trip, contribute to ways of helping others access a place, develop multisensory approaches to engaging in their surroundings and share their experiences to help others. In this paper, we present the initial work supporting the development of a framework for understanding the leisure experiences of BPSP. We explore this theme of contribution and propose a framework where this feeds into each of the stages of leisure experience, resulting in the proposed, PLACES framework (PLan, Access, Contribute, Engage, Share), which aims to provide a foundation for future research on accessibility and outdoor leisure experiences for BPSP and people with disabilities.
\end{abstract}

\section{Author Keywords}

Nature, outdoors, leisure, blind, visual impairment, accessibility.

\section{CCS Concepts}

- Human-centred computing Accessibility Empirical studies in accessibility 


\section{Introduction}

Natural environments such as parks and the countryside1 are ideal for leisure experiences and provide opportunities for relaxation, socializing, and physical activity. Growing research suggests that regular exposure to nature can have a significant positive impact on mental and physical wellbeing [2]. Previous research has also shown that blind and partially sighted people (BPSP) are interested in visiting parks but face numerous challenges accessing and exploring these spaces $[\underline{6}, \underline{65}]$. Current suggestions to improve accessibility and opportunities for engagement for a diverse audience include accessible wayfinding signage, sensory gardens, and multisensory play areas [83]. While such recommendations would improve the accessibility of natural places, in many cases, these are not cost-effective solutions and therefore are often not implemented. Furthermore, none of these solutions would help people explore the physical space in the moment. Currently, in these instances, people must fall back on asking people around them or simply continue unaware of their surroundings.

Sight impairment limits people's independence in mobility and activities of daily living (ADL). Mobility training normally focuses on functional mobility i.e. getting from A to B; is limited to frequently travelled routes. This has the benefit of enabling people to be proficient in their basic functioning (e.g., going to work, shops, etc.). However, beyond these well-trodden routes many BPSP (especially older adults [47]) rely on friends and family, volunteers, and support workers for outdoor recreation.

Recent advancements in mobile technology have aided in independent mobility of BPSP. Mobile applications such as Wayfindr2 and Clew3 help navigate large indoor environments by following virtual audio landmarks. Recent research has also investigated the use of Bluetooth Low Energy (BLE) technology to improve the accessibility of airports [26], train stations [23,45], and museums [49]. Furthermore, assistive technologies (ATs) for outdoor navigation such as BlindSquare 4 and Soundscapes are helping BPSP experience cities in new ways. However, despite the growing potential of technology for independent mobility, current technologies fall short of supporting leisure experiences of BPSP. One of the reasons for a lack of work in this direction is the lack of understanding of independent leisure needs.

To bridge this gap between the existing ATs and the needs of BPSP in outdoor open spaces, we explore the experiences of BPSP when visiting parks and other natural green spaces for leisure. We conducted an online exploratory qualitative survey to investigate how often BPSP visited parks. This was followed up with a focus group, and semi-structured interviews to further explore the needs of BPSP in the context of outdoor leisure, the challenges BPSP experience when planning, accessing, and exploring parks and how do they use technology to overcome these challenges. We also investigate how BPSP use technology when planning visits to parks and to enhance their personal and social park going experience. This paper makes two main contributions; (i) expands the understanding of leisure experiences of BPSP in nature and how technology facilitates these experiences (ii) a framework for designing ATs to support the experiences of BPSP in parks.

\section{Related Work}

We draw on literature from two fields: 1) leisure and tourism to understand leisure experiences; 2) HCI to review how technology supports leisure experiences in natural environments with a focus on BPSP research.

\subsection{Technologies for outdoor leisure experiences}

Leisure experiences are an important contributing factor to a person's well-being. Regular visits to parks have been associated with improving general health and well-being for the general population [1] and participation in social and leisure activities has been shown to improve the quality of life of people with disabilities $[\underline{20}, \underline{47}, \underline{59}]$. Furthermore, the restorative effects of nature and green spaces have been linked with stress reduction [34,43]. Mobile technology has enhanced people's leisure experiences in many ways such as access digital tour guides in museums and tour buses, through mobile apps that enable exploration of new cities while on holiday, and perhaps most commonly through mobile phone cameras to capture memorable moments and social networking sites to share these moments with friends and family.

To further explore the experiences of people when engaged in outdoor leisure Clawson and Knetsch (C\&K) [19] proposed a multi-phased model of outdoor leisure experience consisting of 5 major phases: (1) planning, (2) travel to the site, (3) the on-site activity, (4) return travel, and (5) a recollection. The model provides a structured approach to evaluating group recreational experiences. It has been used to investigate the moods and affective states of participants in response to leisure settings [31,48,70], temporal changes [70], and the impact of these on the overall satisfaction with the experience [31]. Although the model has not been used to understand the leisure experiences of BPSP, it is a useful tool to categorize the literature which exists in this space. We found the existing literature on this can be clustered under phase 2 and phase 4 related to travelling issues. There is a lack of research for phases 1, 3 and 5.

\footnotetext{
1 We use the terms parks, natural environment, natural settings, countryside, and open space interchangeably in this paper to reflect the different terms used in the literature and by our study participants

2 https://www. wayfindr.net

3 https://www.clewapp.org

4 https://www.blindsquare.com/

5 https://www.microsoft.com/en-us/research/product/soundscape/
} 


\subsubsection{Phase 1 - Planning}

Phase 1, planning or anticipation, involves deciding the time, location, and duration of the recreational activity. C\&K suggest that in this phase, the recreationist(s) may plan the cost of the trip, equipment and supplies needed for a successful recreational experience. Although in [19] the model does not elaborate on anticipation, Hammitt [31] noted that anticipation includes imagining the hedonic experiences and activities the participants may engage in during subsequent phases. Anticipation is preceded by acquiring contextual information about the recreational space, e.g. in [31], participants received a one-hour lecture on bog environments prior to the visit which led them to anticipate the wildlife, the visual, auditory, olfactory, and tactile experience of the bog environment.

\subsubsection{Phase 2 and 4 - Travelling to and back from the site}

Phase 2 and 4 are the travelling components of outdoor recreation. Phase 2 involves travelling to the recreation site, with factors such as the travel cost and time known to affect the frequency of recreational visits. $\mathrm{C} \& \mathrm{~K}$ also note enjoyment or unpleasantness of the journey is a variable factor in affecting the overall recreational experience. However, their work does not consider the accessibility of travel, transportation and access to the site, which are some of the key accessibility challenges for BPSP [4,26,45]. For BPSP, travel choices may be limited and they might also find journeys more tiring due to the energy needed to overcome accessibility issues [12,72]. The majority of research focusing on the accessibility of open spaces for BPSP and attempts to make parks accessible include tactile maps, mobile apps and interactive technologies. We discuss these technologies in detail in section 2.2.

\subsubsection{Phase 3 - On-site activity}

Phase 3, on-site activity, includes the main part of leisure experience in C\&K’s model [19]. The range of activities vary depending on the affordance of the space and the recreational preferences of the individuals. In the context of open spaces, technology has the potential to enhance the experience of visitors by enabling interaction, exploration and engagement with nature $[\underline{16}, \underline{28}, \underline{40}, \underline{42}, \underline{71}, \underline{77}, \underline{80}]$. One way of enhancing engagement with nature is through providing location-based information to visitors about the natural landscape and historical information for making the experience more engaging [16]. Ambient Wood [60] uses mobile technologies to enhance the children's learning of nature on a field trip. The project integrated design probes in the environment that allowed students to read data, hear ambient sounds, and watch videos about the biological processes in the woods that normally could not be seen or heard in a traditional field trip. Other similar projects enhance learning experiences in nature [55] and the zoo [56].

Tangible interactive devices have also been developed to increase nature engagement and create awareness about wildlife. Ambient Birdhouse [69], for example, is an internet of things (IoT) device that creates playful interaction while informing the users about the birds that inhabit the urban environment near their homes. Connected seeds [35] and talking plants [36] combine natural elements such as seeds and plants with technology to create engaging interactions with nature. This idea of linking play and the outdoors through technology has also been used to encourage exploration and physical activity in the outdoor environment [3]. Pokémon Go6 is an excellent example of this type of technology, in that it encourages players to go outside and explore in order to 'capture' a Pokémon character and then share this experience [ $\underline{57}, \underline{68}]$. A similar example is Geocaching [며] - a mobile-based GPS enabled treasure hunt app in which players hide small objects such as toys or trinkets in containers and record the GPS coordinates. Other players in the locality of the treasure go 'hunting' and often exchange the item in the container with another when found. Nature Passport app [46] uses goalbased activities to encourage exploration of nearby natural spaces to complete a 'mission'. The user is rewarded with a virtual badge upon completion of a mission.

\subsubsection{Phase 5 - Recollection}

Phase 5, recollection, is the final major phase of the recreational experience which occurs over an extended period, depending on the enjoyment and satisfaction associated with the experience. Recollection influences the re-occurrence of the experience in that the planning and anticipation of future recreational experiences may overlap with recollections of previous experiences [19,38]. Recent research has investigated the use of photographs and video recording to preserve autobiographical experiences and enhance recollection $[17,21,41,53]$. In particular, wearable cameras $[21,53]$ have been used to capture memorable moments periodically based on the wearer's physiological response (heart rate, temperature, etc.) to a stimulus. They have further been used for improving recall and memory rehabilitation in people with dementia []. To the best of our knowledge, existing literature does not consider the blind population and especially what recollection and recounting of an experience is for such a population.

While the above studies do not investigate BPSP people's experiences specifically, they demonstrate that HCI research on interactions with nature is a growing field, supporting people's interest in exploring nature. Audio and haptic modalities have been used to gather information about the natural environment and to encourage engagement with the outdoors and these examples provide useful insights for the design of technology for BPSP. However, they do not inform us about the needs and desires of BPSP to access open spaces.

\subsection{Making public spaces inclusive for BPSP}

Recent research has investigated the accessibility of open spaces for BPSP include tactile maps, mobile apps and interactive technologies. 


\subsubsection{Tactile maps}

Tactile maps consist of raised line maps and braille symbols to indicate wayfinding and signage. They are commonly used in mobility and orientation (O\&M) training. However, tactile maps have become less useful for the blind community as the number of people who can read braille continues to decrease $[85,86,87]$. Tactile maps also lack standardisation regarding map size, symbol options, and aspects of labelling [62] which means it requires a long time to create [61] and understand these maps especially for use for independent travel by BPSP. As an alternative, bespoke 3D-printed models present an opportunity to create low-cost tactile maps of parks and public open spaces for BPSP visitors. Holloway et al [ㄱ] developed guidelines for designing iconography, scale, texture, and complexity of tactile maps. They found that having handheld tactile maps enabled BPSP visitors to develop a mental model of the space and navigate to different parts of the space with little support from companions. Tactile maps have also been augmented with audio information [2] to enhance the navigation experience of BPSP. Tactile maps have also been combined with gesture recognition using a Microsoft Kinect that enabled the construction and exploration of printed and raised line maps by allocating audio output to each landmark in the maps which helped develop a better understanding of the spatial environment [ㄹ].

\subsubsection{Navigation apps and devices}

Although there is little research on inclusive apps for wayfinding in open spaces for BPSP, prior research on blind wayfinding and commercial technology can be useful in exploring open spaces. Mobile apps and devices are increasingly more accessible, for example, allowing magnification or enhanced contrast of texts to enable BPSP to read from non-braille and large-text books. Text-to-speech and VoiceOver functionality in smartphones enable BPSP to access written content by converting it to audio. SeeingAI7 is one such example, which has been adopted by many BPSP as it not only reads out the text but also provides image descriptions. However, despite the growing prevalence, current mobile technology is limited by battery capacity; which is further exacerbated for BPSP due to the use of power-consuming accessibility features like VoiceOver and Zooms. However, as BPSP often do not use the visual user interface, apps like DarkReader [르], provide a power-saving, privacy-preserving screen reader which saves up to $52 \%$ power by turning off the smartphone screen without limiting the user interaction for BPSP.

Research and anecdotal evidence suggest that BPSP use mainstream and assistive navigation apps (RNIB Navigator9, Lazarillo10, Google and Apple maps for navigating routes around the city $[\underline{25}, \underline{78}, \underline{84}]$. Moreover, public transportation; bus and train apps enable BPSP to plan their journeys before travelling; which is essential for independent mobility. Another key mobility skill for BPSP is obstacle avoidance. Research shows that guide dog users can better navigate obstacles as the dog is trained to guide the user away from obstacles in the path [33]. For long cane users, obstacle detection is a big challenge that many researchers have tried to tackle by developing smart canes [12], smart belts [64], clothing [5], and headgear [23]. While most of these devices are still prototypes, some smart canes [22,44,58] have been adopted by BPSP for navigation in areas with obtrusive street furniture and overhanging branches, rooftops, and awnings. Technology for spatial awareness goes a step further in supporting navigation for BPSP by providing additional spatial information in addition to navigation instructions. BlindSquare, Soundscape11, and Trekker Breeze12 are prominent examples of commercial spatial awareness technologies used by BPSP. These apps and devices announce nearby landmarks such as shops, street names, and other landmarks pre-recorded by the user. Footnotes [24] provides more contextual information about the environment; users can annotate functional, visual, historical, and social descriptions of the physical environment which can then be accessed by other BPSP app users. The above studies clearly show that technology for more effective and independent navigation is becoming a reality to BSPS, but they have been designed mainly for the built environment. Navigation in open space may create new challenging questions for navigation technology design. However, most importantly it is clear that it is time to start to understand what leisure experience is for BPSP, what needs it raises and how technology can support this by exploring opportunities in the multiple phases of the leisure experience model [19]. This study aims to develop an in-depth understanding of the needs of BPSP for outdoor leisure experiences in natural settings, considering a multi-phased approach to leisure experience to explore the breadth of design opportunities for HCI research. Our findings lead to a new framework that considers BPSP's perspective on leisure and overcome the limitations of the model proposed by C\&K [19].

\section{STUDY DESIGN}

The purpose of this study was to develop an in-depth understanding of the experience of BPSP in natural environments. We conducted first an on-line survey to further understanding of the willingness of BPSP to visit parks and how technology is used. We focused on parks because they are the main form of outdoor leisure activity more easily available to the broad population in terms of distance from their home. Building on these initial findings, we then conducted interviews and focus group to explore the five phases of [19] and better understand: (i) the needs of BPSP in outdoor leisure, (ii) the challenges BPSP experience when planning, accessing, and exploring parks, (iii) technologies to overcome these challenges. The studies were undertaken with approval from the university ethics committee and are described below.

\footnotetext{
$7 \mathrm{https://www.microsoftcom/en-us/ai/seeing-ai}$

8 https://appleinsider.com/articles/19/06/07/hands-on-with-apples-new-voice-control-accessibility-feature

9 https://apps.apple.com/gb/app/rnib-navigator/id783866151

10 https://www.lazarillo.app/en/

11 https://www.microsoft.com/en-us/research/product/soundscape/

$12 \mathrm{http}$ //support.humanware.com/en-united_kingdom/support/breeze_support
} 


\subsection{Online survey}

We conducted an exploratory survey to investigate how often BPSP spend time outdoors in parks. We recruited 22 BPSP (18< age $<65$ ) with varying visual impairments and degrees of residual vision; 59\% (13) had congenital VI, 23\% (5) had been diagnosed more than 10 years ago, and 18\% (4) more than 5 years ago. The participants were recruited through social media and UK-based organisations working with BPSP. We used Qualtrics13 platform hosted by the university for General Data Protection Regulation (GDPR) compliance to run the survey between June and September 2019. The survey consisted of closed questions related to demographics and visual impairments to understand participants' personal circumstances and open-ended questions to capture free-form answers based on their personal experiences14. We refer to survey participants in this paper as SP1-SP22.

\subsection{Interviews}

After having established that BPSP were interested in regularly spending time in parks and other natural open spaces, we conducted semi-structured interviews with 20 BPSP (11 male, 9 female) to further investigate how BPSP experience outdoor nature. The interviews lasted between 30 and 80 minutes and were conducted over the phone and Skype to include people from a diverse set of geographical places. The interview began with background questions about the person's general interest in outdoor leisure activities, what they found enjoyable and what they found challenging. We further asked probing questions focusing on participants' narrative accounts of their personal experiences. This enabled the participants to speak more freely and recall details of the multi-sensory, affective and social aspects of their previous experiences in nature. The interviews addressed two main research questions;

- RQ1: How do BPSP: (i) plan for visits to outdoor natural spaces? (ii) access these spaces? (iii) engage with the environment?

- $\quad$ RQ2: How do the current technologies facilitate these experiences? 
Table 1: Interview (P) and focus group (FG) participant description. $G=$ Gender (Female, Male), Onset $=$ Age at onset of sight loss $(0=$ at birth, $\mathrm{n} / \mathrm{a}=$ not available).

\begin{tabular}{|c|c|c|c|c|c|}
\hline P\# & Age & $\mathrm{G}$ & Onset & Visual impairment & Places visited \\
\hline \multicolumn{6}{|c|}{ Interview Participants } \\
\hline P01 & 28 & $\mathrm{M}$ & 14 & Partially sighted & Urban parks \\
\hline P02 & 40 & $\mathrm{~F}$ & 0 & Totally blind & Urban parks \\
\hline P03 & 62 & M & 0 & Totally blind & Urban parks \\
\hline P04 & 38 & $\mathrm{~F}$ & 0 & No depth perception, no binocular vision & Urban parks \\
\hline P05 & 42 & $\mathrm{~F}$ & 0 & No vision in right eye; $2 \%$ in right eye & Urban parks \\
\hline P06 & 25 & M & 0 & Partially sighted & Urban parks \\
\hline P07 & 35 & M & 0 & Partially sighted & Urban parks \\
\hline P08 & 56 & M & 0 & Partially sighted; night blindness & Woods; urban parks \\
\hline P09 & 61 & M & 53 & Total blindness & Urban parks \\
\hline P10 & 36 & M & 24 & Totally blind & Urban parks \\
\hline P11 & 60 & M & 0 & Totally blind & Urban parks \\
\hline P12 & 36 & $\mathrm{~F}$ & 0 & Totally blind & Urban parks \\
\hline P13 & 65 & M & 0 & Totally blind & Urban parks \\
\hline P14 & 40 & $\mathrm{~F}$ & 10 & Totally blind & Hiking \\
\hline P15 & 50 & M & 0 & Totally blind & Forests \\
\hline P16 & 60 & M & 0 & Totally blind & Urban parks \\
\hline P17 & 26 & $\mathrm{~F}$ & 0 & Light perception, colour contrast & Forests, urban parks \\
\hline P18 & 25 & $\mathrm{~F}$ & 0 & Light perception, large shapes & Lake side \\
\hline P19 & 35 & $\mathrm{~F}$ & 0 & Light perception & Hiking, urban parks \\
\hline P20 & 40 & $\mathrm{~F}$ & 17 & Light perception, colour contrast & Hiking, urban parks \\
\hline \multicolumn{6}{|c|}{ Focus Group Participants } \\
\hline FG1 & 28 & $M$ & $\mathrm{n} / \mathrm{a}$ & Partially sighted & Urban parks \\
\hline FG2 & 31 & M & 3 & Totally blind & Urban parks \\
\hline FG3 & 50 & $\mathrm{~F}$ & 0 & Totally blind & Urban parks \\
\hline FG4 & $70 \mathrm{~s}$ & $\mathrm{~F}$ & $\mathrm{n} / \mathrm{a}$ & Partially sighted & Urban parks \\
\hline FG5 & $70 \mathrm{~s}$ & $\mathrm{~F}$ & $\mathrm{n} / \mathrm{a}$ & Partially sighted & Urban parks \\
\hline FG6 & 80 & M & $\mathrm{n} / \mathrm{a}$ & Partially sighted & Forests, urban parks \\
\hline FG7 & 78 & M & $\mathrm{n} / \mathrm{a}$ & Partially sighted & Urban parks, garden \\
\hline FG8 & 82 & M & $\mathrm{n} / \mathrm{a}$ & Partially sighted & Urban parks, garden \\
\hline FG9 & 35 & M & $\mathrm{n} / \mathrm{a}$ & Partially sighted & Forests, urban parks \\
\hline FG10 & 36 & $M$ & $\mathrm{n} / \mathrm{a}$ & None; support worker & $\mathrm{n} / \mathrm{a}$ \\
\hline
\end{tabular}

\subsection{Focus group}

To supplement the interviews and expand the discussion on "barriers to nature engagement for BPSP," we conducted a focus group with 9 BPSP (4 male, 5 female), two of the participants had no light perception and seven had partial vision; one of the participants was a support worker (female) accompanying a participant who was recruited opportunistically to include her unique perspective on providing support and companionship for BPSP in leisure activities. The focus group discussion ran for 70 minutes. All participants were active 
users of smartphones and other digital technology. The focus group discussion aimed to address the research question; RQ3: "What are the barriers and enablers in leisure activities for BPSP?”. The initial questions explored participants' previous experiences in nature. The participants also discussed how they used technology to support their outdoor experiences. Table 1 lists participants' information and types of parks and green spaces they visit for outdoor leisure.

\subsection{Data analysis}

To address our research questions, we followed a deductive thematic analysis approach [18] to generate themes. Initial codes were applied to open-ended survey questions, interviews, and focus group data deductively based on C\&K [19] phases; plan or anticipation, travel to the site, and on-site activity. Additionally, we developed the theme 'Technology use' to address RQ2. We used NVivo15 to organize the codes and categorize them into four major stages of leisure experience; (1) planning, (2) accessing, (3) engaging, (4) sharing and recollection. We began by deducing the data pertinent to the C\&K model; phases 2 and 4 were combined into 'Access' as 'return travel' did not emerge as a significant concept from our data. We discuss our framework in detail in section 5.

\section{Findings}

Below we present findings from aforementioned studies grouped in the four stages of leisure experience; Plan, Access, Engage, and Share.

\subsection{Plan}

Planning a leisure experience for BPSP involved gathering detailed information to understand the environment and collaborative decision-making with sighted companions. Many BPSP plan the details prior to visiting to ensure there are no unexpected issues while travelling and need accessible information ahead of the visit. When planning visits to natural sites, participants information needs varied depending on the type of activity, whether they were going alone, meeting someone at the destination, or travelling with a companion. Most importantly, participants wanted to know if the place was accessible ( "We go to places that are disabled accessible," SP2), provided appropriate spots for rest and relaxation ( "How to find out accessible roots or bench or other points of interest along walks," SP18). Having a sense of familiarity with the space increased participants' confidence ( I tend to visit places I'm familiar with. I like to have a good understanding of the area, the trails, terrain etc, "SP17).

Beyond the typical information necessary to access and enjoy the space, planning was in itself an activity people wanted to be part of. Indeed, some participants described planning as a collaborative process with their sighted companions. This was particularly true for visiting places participants had not visited before and were unable to find information about on their own ( My husband needed to plan it. Because I just don't know where to find the information that you can look up a special hiking map app and charts that people make of how long the hikes etc. We went hiking in the national park and he asked me how long the hike I want, and he found one and then I couldn't have gotten there by myself anyway., " P14). Still, for many participants, this was an activity that they feel they were left out. Various participants associated planning with autonomy and wished for more autonomy in planning and being able to contribute to the planning process ( I don't really get involved in the planning. They (family) usually decide where we're going, I feel that I can't contribute to what' the place should look like.,"P17). All participants reported going to the parks with friends, family, or support workers.

The importance of participating in planning also emerged from how the companions would talk about help. Some participants expressed frustration at the lack of autonomy in choosing their leisure activities but their companions mainly reported on their desire to help ( "They are grateful when they shouldn't have to be.," FG10) without considering the meaning of that frustration ("People that are visually impaired are grateful that you're there to guide so they kind of go with the flow, "FG10). While help was surely well-received by BPSP, it falls short to provide a sense of independence and willingness to visit new places.

\subsubsection{Technology for Plan}

A common use of AT was the smartphone text-to-speech feature which enabled participants to access various apps and features of their phones. Participants with significant residual functional vision also used the zoom or magnifying feature in their smartphones to magnify smartphone screens and the Magnify feature which uses the phone camera to magnify text and objects. Magnify was especially useful when reading signage and printed maps outdoors [72]. Some partially sighted participants also used a magnifying glass and standalone video magnifiers like SmartLux Digital 16 for reading.

Participants described different ways technology could enhance their leisure experiences in parks. When planning a visit, participants desired to have contextual information about parks available on an accessible website ("Information that is available visually [in parks] could also be posted on accessible web pages so that a screen reader user could use their phone to read the information," SP6).

\subsection{Access}

Various sub-themes emerged in relation to access to parks; finding park entrance, wayfinding inside the park, leaving the park, and obstacle avoidance.

15 https://www.qsinternational.com/nvivo-qualitative-data-analysis-software/about/nvivo

16 https://www.eschenbach.com/products/video-magnifiers-handheld-smartlux-digital.asp 


\subsubsection{Finding park entrances}

Finding the entrance to the park was identified as one of the critical barriers to visiting any park. Size of the open space and lack of physical boundaries contributed to this problem. Participants showed a preference for pocket parks; small green spaces within the urban city space, over large parks due to the relatively smaller size of the open space and vicinity to transportation. Participants emphasised entrances to large parks were challenging ("Some of the parks have a lot of entrances. So, there's north side, south side, etc. Finding the right entrance to the park is a challenge.," FG2), especially when travelling alone to meet friends at the park ("Couple of weeks ago, we planned a meeting in a park. We're all BPS and it's a massive park, we couldn't find each other," FG2). The problem of size for large parks was partially alleviated by the lack of fenced boundaries typical of common green spaces which were easy to access on foot or via transport ( "Easy to get to via transport and clear journey rather than lots of different roads etc.," SP1).

\subsubsection{Wayfinding inside the park}

Once entered, wayfinding inside the park was the most challenging part of the park experience. BPSP learn to use the built environment landmarks and clues such as building lines, road crossings, and the sounds of traffic to make sense of their environment. However, parks and open spaces lack these landmarks and cues, making these spaces disorientating and challenging for BPSP to navigate. Most participants suggested better navigation inside the parks would significantly improve their experience and confidence to explore the natural environment. This is best described by SP7: "Better way of navigating the open space. At the moment I am worried I would get lost without any backup so tend not to go to these types of places on my own.," SP7.

\subsubsection{Leaving the park}

Finally leaving the park was as critical as entering it. Older participants (70 and above) in the focus group did not visit parks regularly due to the fear of 'not being able to find their way out'. One participant (FG8) described her experience of almost getting 'locked in the park' as she was unable to find her way out and the impact that this experience has had on her wellbeing - she no longer visits local parks. FG2 also mentioned feeling disoriented and not being able to find the path to exit the park ( I find it really difficult to find my way out [..]. It's like mission impossible. I use echolocation, so I click and sometimes it helps but, in a park, there are no walls to feedback from and things like that so it's really difficult to find my way out of the park, "FG2).

\subsubsection{Obstacle avoidance}

Obstacle avoidance in the park was another main issue for long cane users ( "unless you have a guide dog. It's really impossible to get around the park, ”FG3). The fear of 'falling' was indeed one of the reasons people avoided parks. Upon receiving mobility training, BPSP can confidently use a long cane for navigation and obstacle detection by sweeping the long cane on the path to detect obstacles and tapping the cane from side to side to avoid veering. Although a long cane is the most common mobility aid used by BPSP, it is only effective for detecting large on the ground obstacles. Participants found it challenging to navigate using their long cane in parks as grass ("Sometimes canes are highly annoying in grass because they'll get stuck and you end up hurting yourself with your cane," P18) [6] and avoiding overhead obstacles ("Seeing unexpected obstacles such as fallen debris or low over-hanging bushes," SP17) were a challenge. Veering was a common issue for participants when walking in the open space without a structured path, one participant adapted their long cane techniques to navigate the irregular terrain while hiking ("My cane technique is different, I use it back and forth on the path. I use my cane to find the path and the edges to stay on the path that feels more like dirt," P14). Uneven paths and surfaces were also difficult to navigate as BPSP could not predict changes in the walking terrain. Many participants reported that they would like to know the path layout and different types of terrain in the park to decide whether the terrain would be safe for them to walk on and mentally prepare before visiting.

\subsubsection{Technology for Access}

For outdoor mobility, most participants had memorised their frequently travelled routes from mobility training with an instructor or repeated travel with a sighted guide and turned to technology when travelling a new route or exploring a city. Participants reported using navigation apps BlindSquare and Soundscape when travelling in the city ( "When I'm navigating the streets [..] I'm experimenting with various apps that are available for navigation," P13). However, the navigation data in small towns was less accurate ("I have used it in my small town. It is not quite as updated," P18). The little information provided by the apps was still useful for BPSP to explore their town ("it can be very useful when new things come to town and I don't know about them and exploring different areas," P18). Navigation apps were less used in parks and other open spaces as participants noted that the apps did not have accurate street maps and spatial information once they were inside the park ( "Certainly once you leave a street, once you're in open land that isn't part of a street map, those are not very helpful really. I don't use anything like that really. I just walk usually with whoever is with me on the walk.," P16). P15, who is a keen rambler mentioned using the 'Rambler App17' which has information about walking routes across the UK, but found several accessibility issues that made the app impossible to use ("there are various buttons on the app that make it really impossible for me to use and extract the information back out again”).

BPSP are familiar with tactile and raised line maps as these maps are used in mobility training to help BPSP learn new routes. Participants suggested having access to tactile maps would help build a mental map [50] of the park environment and access different parts of the park ("Even to be able to access all parts of the park and find your way out, to know that you can get out when you need to. You know where all the gates are, where the facilities are, and what the facilities are. Like, for sighted people, there's usually a map isn't there? That says what's in that park so like the toilets and..," FG3). Some participants noted augmenting tactile maps with audio 
information about their surroundings and about different parts of the park would make their experience of exploring parks more enjoyable ("There could be a screen you can touch it and it will show you where the cafes are or where you are, or there's a button to press that speaks.," FG3). Additionally, when exploring the natural environment, ("[portable] tactile maps or drawing in conjunction with text description," SP4) were described as potentially useful as well as tactile objects and models made of recycled materials to help understand the size and shape of bird species and flowers which cannot be touched directly.

Privacy and discretion was important, desired technology to enable access to the environment in a non-obtrusive way ("wayfinding technology using Bluetooth transmitters located at various locations in a park, with an app or specialist device to interact with them in a private discrete fashion such as through bone-conducting headphones," SP5).

A novel concept that emerged from the focus group to address the access-to-the-park problem was a 'park hub' to support BPSP visitors located at different parts of the park and information about park facilities. Participants suggested that this 'hub' could support people with' diverse needs and could make parks more inclusive for people with other disabilities. A 'hub' could also enable people with disabilities to contribute to the community by offering their skills and support to park visitors. For example, one participant commented ("Perhaps people with different disabilities could help one another. Maybe somebody with a wheelchair could help someone who's blind.,"FG3). As for the planning phase, being able to contribute to enabling the experience was important to the experience itself.

\subsection{Engage}

Participants engaged in a variety of physical, social and relaxing activities in parks, which involved 'walking', 'cycling', 'running', 'spending time with family and friends', 'escaping the city', 'exploring nature', and 'drawing', 'photography', and 'writing'. Some participants, who are guide dog users, regularly visited parks for 'dog walking' and to relax and enjoy nature while the guide dog enjoyed free-running ("The space to breathe fresh air. Area for my guide dog to relax/free run. Hearing sounds of nature wind or birds/animals, "SP11). Participants described their pleasant moments of spending time with their family and recollecting their previous visual experiences of the place ( "Feeling the weather, hearing birds, playing with my son, imagining the world around me that I remember,"P15).

\subsubsection{Multi-sensory immersive experience}

Participants appreciated the immersive experience of being around nature. They described feeling 'relaxed' (13 participants), 'happy' (P14, P18) and 'excited' (P13, 14) when being around nature ("Ilove creation. I love the trees and the sound of wind through the leaves," P15). A theme that emerged as important was the building of a multi-sensory image of the surrounding. A participant commented for example on the multisensory experience of nature ("I try to picture them [plants] so that I have a picture of the environment and the audio and tactile really adds to the experience," P14). Participants suggested that audio descriptions were valuable in developing mental images and making the space and experience memorable ("The whole atmospheric thing of hearing the wind in the trees, the sheep, and the birds, and that sort of thing. That's the experience that I like," P13). Another interesting theme that emerged was the role of the companion in building multi-sensory images of the environment. As most participants visited parks with sighted companions, they often discussed the multisensory sensations of the environment. Companion not only co-experience the environment but contributed to identifying sources of sensory experience. For example, companions supported the participants by pointing out points of interest and facilitating tactile interactions, as P13 noted ("Touch is important. Occasionally, if we're out and about my wife will say, Well, there's a particularly interesting tree or if there are wooden sculptures of animals, we would go look at [and touch] them, ”).

\subsubsection{Sensemaking and learning about nature}

Generally, participants were also interested in knowing about the visual aspects of the surrounding and often asked their companions to describe the visual environment in response to auditory and olfactory stimuli they felt ("what kind of flowers are there? What colour are they?" P18). Some participants described a feeling of loss and disconnection from nature after sight loss and not being able to enjoy the visual detail of nature ("Can no longer go close to a flower to see it up close and enjoy its detail," SP14). Companion contributed to filling in gaps in the multi-sensory experiences by sharing their visual modality and building the image together. P18 noted a memorable occurrence from her recent experience to a nearby lake with her grandmother created a sense of shared experience through exploring the multisensory sensations with her companion ("I heard some splashing and at first I thought there were some fish jumping because there is a lot of that too. They will just flop around and make sounds in the water. That's what I thought it was at first and then she says, "Oh my god, there are ducks swimming up to the shore now!" And I think my question was "Really? baby ducks or older ducks?" And she told me that there were one bigger one and a couple of babies. And then I asked,"). Interestingly, some of these participants had ( "never seen colours") but still asked about this in order to ("to get as much information as I possibly can").

Beyond building multi-sensory experiences supported by a shared sensory system with the companion, learning about the history of the place was also part of the experience people were looking for. Participants were interested in learning about the historical significance of the places, specifically, when visiting heritage sites, they preferred being told about the ("background and maybe history of the place and an overview of the layout," P15). This was further expanded on by another participant who shared a recent experience ("the actual material that they presented was really interesting. They were talking about the way that the Anglo-Saxons associated properties of the environment with spirit, with gods, deities, and the way that those properties turned into a written-effectively, a written language.," P11). 


\subsubsection{Technology to Engage}

Participants mentioned technology could be useful to engage with the environment. ("Where things are and what's around me, SP16). In particular, participants were interested in technology to help identify nature e.g. species of birds, flowers, and trees that inhabit the area. ("I would like to know what trees there are, plants, colours and name of flowers, and birds," SP18). Frequently these elements nature and landmarks - were combined with information about what was happening in real-time. ("What birds are flying over, plants, what landmarks like rivers or lakes are in the area and how to safely get to them," SP22) and also for general information. ("[...] the area, and the animals and plants in it. Maybe some information-based app, if you type in the park you are in and it gives you information," SP11). Some participants with partial residual vision used a handheld magnifying glass to read signposts and to extend their vision, as P07 noted ("I've always carried around all my life is a little monocular, a little telescope. It's useful for reading signs, for looking at buses when they're coming. It's incredibly handy for extending my distance vision,").

Although many participants were interested in mobile apps for exploring parks and nature, not everyone wanted to use technology during a visit to avoid distractions or interference with the quality of their experience ( I don't like babbling technology ruining the quiet ambience of a natural environment. It detracts from the experience of the moment. I can learn about the environment before I go or after I return from it," SP19)". This interesting finding highlights the need for being flexible in making information accessible not just in the natural environment but also outside of it to provide BPSP visitors with the choice to access it even during planning or after the visit. This example also highlights the need for tailoring technological solutions to the personalities and preferences of individual BPSP. When reflecting on technology use during a visit, participants also expressed concern that constant navigation app use could cause 'battery drainage' and make it challenging for them to get back home.

\subsection{Share and recollect}

Technology use was more pervasive in how participants recorded and shared their experiences. Participants reported that they recorded memorable events to share with the wider BPSP community and enjoyed sharing these experiences on social media. Participants with significant residual vision described taking pictures, 'checking-in' their location on location sharing platforms and recording 'video blogs or vlogs' to share on social media ( "We take selfies and post on Facebook and I have recently started vlogging so I record YouTube videos as well," P18). Participants without residual vision described capturing wildlife sounds, recording wayfinding instructions, and other contextual information about the environment for their own engagement and recollection ("I like listening to them back and hearing the sounds again. Sometimes it just makes me want to be in the place where I recorded them, ” P14). They desired to share these recordings with others but were unable to due to lack of accessible tools and platform ("I would love to share them on the internet but then I have to do a little editing and I'm no audio editor," P14).

The importance of contributing to enable the experience of others emerged also in relation to this last phase of the outdoor experience A concern shared by the participants when discussing planning leisure experiences was the accessibility of detailed information about parks for BPSP. It was also important that the information was given from the perspective of a BPSP visitor and one of the suggestions was for BPSP to share their experience of visiting places with the community to benefit others in understanding the environment. Participants regularly shared practical information about the place and navigation strategies such as length of the walking route and important landmarks ("I suppose just the distance of the walk and then I suppose I get them to have a look for themselves [on online maps]," P15). They also suggested sharing wayfinding information could be a way to increase engagement of the blind community with natural settings as more people would be interested to visit ("If somebody without sight has done a particular route and built up their own landmarks then it would be good if you could tap into what they have already done. Wouldn't it? Sort of sharing of information within the community," P15). Another suggested sharing practical tips such as best clothes to wear, choice of footwear, the difficulty of the walking terrain, and best picnic spots with friends and family from the perspective of a BPSP could also be useful when planning visits.

The desire to share did not stop at information sharing and facilitating access for others. Participants expressed a strong sense of community with other BPSP and a desire to enable others, especially BPSP with limited outdoor experiences. One participant, who produces a monthly audio newsletter for BPSP reflected on the impact of sharing experiences with others ( "The people that listen to it are pretty much housebound and in some cases, very isolated... we heard from a lady who said that we were the only friends that she had over for Christmas. To me, if there's one person that feels that, then it's worth doing," P11).

\section{PLACES FRAMEWORK}

Initially, we aimed to identify the needs of BPSP at the plan, access, and engage stages of their leisure experiences and the barriers they faced, mapped to the outdoor recreation model [19], to investigate how current technology addresses these needs. Table 2 illustrates the needs of BPSP in each stage and how they are addressed by them. We designed our initial interviews based on this initial understanding of the leisure experience from an individual's perspective. The PLACES framework (PLan, Access, Contribute, Engage, and Share) builds on the model [19], but it proposes significant modifications to the original phases.

In PLACES, 'Plan' incorporates the needs of BPSP when preparing for a trip, 'Access'incorporates both transport to and from the venue as well as wayfinding within the park. Further, we consider 'Engage' as a distinct element as the evidence from our study shows that the barriers experienced by BPSP in open spaces may hinder participation in the on-site activity. Finally, 'Share and recollect' incorporates both personal recollection and sharing leisure experiences with others and expands the idea of 'sharing to cultivate engagement within the BPSP community'. 
Table 2: Initial PLACES framework

\begin{tabular}{|c|c|c|}
\hline Stage & Needs & Challenges and strategies \\
\hline Plan (PL) & $\begin{array}{l}\text { - Where am I going? } \\
\text { - Who am I going with? } \\
\text { - What will I do there? } \\
\text { - How will I get there? } \\
\text { - } \quad \text { How will I meet my friends there?) }\end{array}$ & $\begin{array}{l}\text { Rely on sighted family members and } \\
\text { companions to meet their planning needs. } \\
\text { Use accessible navigation and public } \\
\text { transport apps to plan their journeys. }\end{array}$ \\
\hline Access $(A)$ & $\begin{array}{l}\text { - How do I find the entrance? } \\
\text { - How do I get to the areas I need to go to? } \\
\text { - } \quad \text { toilets, cycle rack, car parks? } \\
\text { - How do I avoid falling? }\end{array}$ & $\begin{array}{l}\text { - Challenging to access parks and facilities } \\
\text { without sighted help due to the lack of } \\
\text { tactile and auditory wayfinding information } \\
\text { in parks. } \\
\text { - Prefer small size parks or no-fenced parks } \\
\text { to overcome entrance and orientation } \\
\text { challenges. }\end{array}$ \\
\hline Contribute (C) & $\begin{array}{l}\text { - How can I contribute to the plan? } \\
\text { - How can I help others to access? } \\
\text { - What abilities I have to offer to others? } \\
\text { outdoor experience? }\end{array}$ & $\begin{array}{l}\text { Want to be part of the decision-making and } \\
\text { sharing abilities with people with other } \\
\text { disabilities. }\end{array}$ \\
\hline Engage (E) & $\begin{array}{l}\text { - What's around me? } \\
\text { - What plants and animal life are in this space? } \\
\text { - } \quad \text { mew can I make sense of the nature around } \\
\text { How do I build rich multisensory experiences? }\end{array}$ & $\begin{array}{l}\text { Rely on companions' visual sense to build } \\
\text { mental pictures of their surroundings. } \\
\text { Explore their surroundings through } \\
\text { auditory, tactile, and olfactory senses, } \\
\text { helped by their sighted companions. }\end{array}$ \\
\hline $\begin{array}{l}\text { Share and } \\
\text { recollect (S) }\end{array}$ & $\begin{array}{l}\text { - How can I capture the multisensory } \\
\text { - } \quad \text { Howsations and share them with others? } \\
\text { experience with other BPSP to help them } \\
\text { plan? }\end{array}$ & $\begin{array}{l}\text { Desire to share their experience further } \\
\text { with other BPSP and publicly over the } \\
\text { internet but faced accessibility challenges. } \\
\text { Capture nature sounds for personal } \\
\text { recollection and sharing with friends. }\end{array}$ \\
\hline
\end{tabular}

\subsection{Contribution as an overarching concept}

The idea of 'contribution' - of people wishing to contribute to each stage of the leisure experience emerged as an overarching concept across the four stages. Participants desired to contribute to planning by sharing their interests and concerns with their companions. They also wanted to collaboratively make decisions about where to go, how to get there, where to stay (for longer trips), etc. Being able to contribute planning would not only give BPSP more 'say' in decision-making, but they would also learn more about the place they're going to, which would lead to more independence in 'Access'. Furthermore, participants experienced 'engagement' as a social activity. They enjoyed co-creating shared sensory experiences with their companions and felt their contribution was validated as they had an enhanced auditory, tactile, and olfactory experience compared to their companions - they created interdependent experiences. As P14 noted, she would draw the attention of her companion towards the sounds and smells of the surrounding. P18 explored the environment by listening for sounds that captured her attention and sharing these with her grandmother. These episodes of close social interactions while engaging with nature highlight collective multisensory sense-making. Therefore, in the final framework (illustrated in Figure 1), 'Contribute (C)' is presented as a key element.

\section{Discussion}

\subsection{Collaborating in planning leisure activities}

Planning is a critical step for BPSP which includes obtaining detailed information about the place prior to a visit. Many BPSP would only visit the environments they are familiar with and hence are comfortable navigating and avoid visiting new places unless accompanied by someone. This is in keeping with prior work [6]. We found that the lack of information available to BPSP to meet their needs is one of the core reasons for their lack of interest in visiting parks. A lack of information has also been found to be a barrier to travel rips more generally e.g. bus [15] and city trips]. We found access to prior information about the park layout, facilities, and accessible wayfinding are key factors in planning. Currently, participants often depended on friends, family, and other support to access 
the information online. In this way, their ultimate interaction with nature is mediated through supported interactions with technology (in this case friends looking up information online). The concept of supported interactions between visually impaired people and technology has been studied previously. For example, Berger found supported interactions enabled deeper connections between participants and 'supporters' [7]. Furthermore, such interactions have been shown to promote a sense of community and interdependence among BPSP and supporters [ $[\underline{10}]$. This sense of community is also a fuel for such interaction $[\underline{7}, \underline{10}]$.

Within disability theory, interdependence has emerged as a framing which goes beyond the idea of campaigning for or designing for independence; for it is impossible to be truly independent as a person within a community and society [51,67]. Bennett et al [10] have explored this concept in relation to assistive technology. In our study the interplay between 'interdependence', and 'independence' was highlighted, during the planning stage, our participants did not wish for 'independence', due to the nature of leisure being a social activity; instead, they desired to collaborate in planning with others and collaboratively make in decisions.

\subsection{Creating a shared sensory experience}

Our findings reveal that BPSP are interested in various physical and social activities in parks as well as engaging with the surrounding nature and wildlife by learning about the environmental, historical, and social context of their surroundings. These findings are aligned with recent research on HCI and digital technologies for supporting engagement with nature [28] for non-BPSP. For example, recent work on tangible interactions with nature for promoting nature empathy and conservation [69] can be expanded to BPSP as tactile and auditory modalities are primary ways people with significant sight impairment experience their environments. Similarly, virtual and augmented reality applications for enhancing cultural and heritage experiences $[\underline{29}, \underline{30}]$ can also be made inclusive to BPSP by exploring multiple modalities. Our findings also highlight how participants appreciated the multisensory experience of being in natural environments and enjoyed engaging in a shared experience with their companions from the multisensory sensations afforded by nature and combining their sensing capabilities almost into an enhanced sensorial experience. The idea of co-creation of a shared experience which we found, complements research on collective sense-making between people with different visual disabilities when exploring a new city [72] and creating an accessible home environment [13]. It also expands on the concept of contribution and in turn on interdependence. The desire expressed by our participants to co-explore and make sense of a new place together with those they were with mirrors the example of people shopping given in [10] where two people collectively made sense of their shopping experience.

\subsection{Sharing to foster social relations}

While we did not consider 'recollection' and 'sharing' of leisure experience at the beginning of the study due to our primary interest in the first three phases of C\&K's model, these concepts emerged in interviews when participants were asked to describe their recent outdoor experience. C\&K's model [19] suggests that 'recollection' is the fifth major phase of a leisure experience which emphasises the individual's personal recollection of the events. This recollection concept has been studied in previous work in relation to travel photos and souvenirs $[17, \underline{41}]$ where researchers found that taking photos of meaningful moments improved participants' satisfaction with and positive recollection of the experience. This is often achieved through after the fact sharing of the photographs with others. Our findings show that participants draw satisfaction from being able to share the experience with others in the place, online, capturing moments for personal recollection and sharing, and sharing the experience with other BPSPs to foster a strong sense of community. Photo sharing behaviour among BPSP has been explored in recent research [1,11,27,39,73,74,76] and found that BPSP participants were interested in taking and sharing photos of their experience with their sighted and BPSP friends. However, common issues experienced when taking photos included needing sighted help to frame the camera and capture good quality photos [1,11], confidence in sharing platforms such as social networking sites [11], and attaching appropriate audio descriptions of the scene to the photos [32]. In alignment with previous research [11,75], our findings show that BPSP wanted to capture moments from their experience and share them with their friends on social networks. Our findings further highlight that sharing strategies varied between participants and correlated with residual functional vision [11]. Participants with no residual vision did not mention capturing photos and videos, but described recording themselves and their children playing, sounds from surrounding wildlife, and other environmental sounds for recollection and sharing. While attaching audio recording to photos for description has been researched with BPSP, recording and sharing of voice memos for recollection is a novel finding emerging from our study.

\subsection{Technology as a facilitator}

Our findings revealed that participants actively used apps and devices in their homes and outdoors for independent mobility. They also used accessible websites and public transportation apps for planning their journeys and map apps for real-time navigation instructions. These apps are helpful in getting BPSP from their homes to public transport and finally near the park entrance but not once inside the park.

One of the biggest challenges BPSP currently experience when using the navigation apps is not being able to navigate inside the parks due to lack of appropriate navigation data of walking paths within parks. Moreover, currently available technologies do not support BPSP in exploring the park environment, engaging in leisure activities, and discovering the surrounding nature in the moment. Mobile 
apps such as PictureThis18, PlantSnap19, iNaturalist20, and PlantNet21 are among many apps that aim to identify plants from an image search. Warblr22 (also referred to as 'Shazam for birds'), BirdUp23, and Chirp! 24 are among few that recognise birdsong from an audio recording. Although there is a lack of formal evidence of accessibility, these apps indicate growth in research and design of technologies for engaging with nature. Future designs in this space should consider ability-based design [10,79] to allow people with different visual abilities to collaboratively explore and engage with nature.

Another important challenge is the availability of inclusive information about park accessibility for BPSP. One such example is Accessable 25 which provides accessibility information about public places including restaurants, hotels, cinemas, and universities. The information, however, was limited to a small number of locations in the UK. In this space, crowdsourcing accessible information [24,63] about parks and other public spaces can create more leisure opportunities for BPSP and people with disabilities.

Despite the availability of technology for exploration, many people were still unable to access the parks and explore surroundings once there [66]. In some cases, this was because a general-purpose application like Google maps did not fit the needs of the BPSP despite being accessible to use as it lacked the necessary accuracy to navigate open spaces. In other instances, people appeared unaware of applications and finally some applications were simply not accessible to BPSP - something which is unacceptable.

\subsection{Limitations and future work}

Our survey design made a trade-off between ease of participation and collection of comprehensive demographic information. As the primary aim of the exploratory survey was to capture park going experiences of BPSP, it was not deemed essential to make demographic information questions mandatory, leading to over half our survey participants not responding to them. Additionally, age at onset of sight loss could not be captured for all focus group participants due to limited discussion time. Thus, we have not considered age, employment status, and location of the participants in the current study.

Furthermore, many focus group participants were above 75 years, which may not be a representative sample considering the overall age range of study participants. One advantage of this was that older participants had more previous experience of natural environments before sight loss and desire to continue visiting.

Although our work focuses on the needs of BPSP, we propose that the PLACES framework can be used to understand the needs of, and challenges experienced by people with other disabilities, but this needs further investigation with the target population.

Finally, though our findings reveal a rich picture of how both BPSP and their companions contribute to creating a shared social experience, we did not consider this interdependence when planning this study. Future work in this space should consider dyadic observations and interviews $[\underline{14}, \underline{52}]$ with BPSP and their companions to investigate interdependent interactions when creating shared social experiences.

\section{CONCLUSION}

In this paper, we report on our studies to explore the needs of BPSP in leisure experiences in parks through an exploratory online survey, interviews, and a focus group study. Our findings highlight the significance of outdoor leisure experiences for BPSP and the importance of considering the inclusion of populations with different abilities in outdoor leisure experiences in HCI more generally. We identified issues that characterise the different phases of the park going experiences of BPSP and proposed a framework called PLACES to highlight the critical nature of the contribution of BPSP across the stages of a visit to a park, which helped to elicit design directions such as apps for audio sharing of experiences. Future research should address the needs of BPSP for active contribution in planning, executing and reminiscing about leisure experiences, and the interdependence of these interactions. The impact of such new technology is best described by P15:

".... It would just be liberating and fantastically independent. [...] You could say, 'oh that forest in the distance over there is such and such forest and if we carry on 2 miles along this route then we're gonna get to a café.' So, it enables you to inform other people or have better conversations with those around you that can see. So, you can join in a bit more,"

\section{ACKNOWLEDGMENTS}

We thank our study participants for sharing their experiences and valuable insights. This work is funded by Engineering and Physical Sciences Research Council (EPSRC) Doctoral Training Program EP/N509577/1.

\section{REFERENCES}

$<$ bib id="bib1" $><$ number $>1 .<$ /number $>$ Dustin Adams, Lourdes Morales, and Sri Kurniawan. 2013. A qualitative study to support a blind photography mobile application. $A C M$ International Conference Proceeding Series, ACM Press, 1-8.</bib>

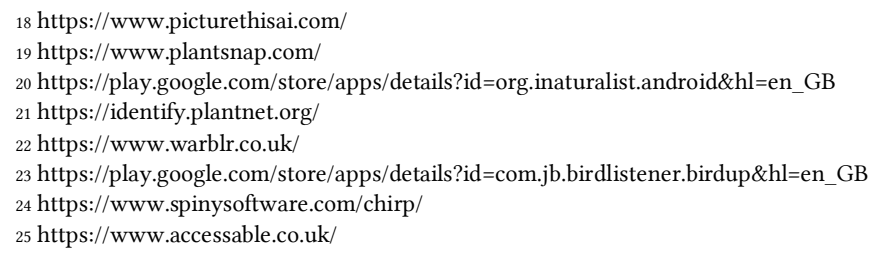


$<$ bib id="bib2"><number>2. </number>Jérémy Albouys-Perrois, Jérémy Laviole, Carine Briant, and Anke Brock. 2018. Towards a Multisensory Augmented Reality Map for Blind and Low Vision People: a Participatory Design Approach. CHI'18 - CHI Conference on Human Factors in Computing Systems, ACM Press, 1-14.</bib> $<$ bib id="bib3" $><$ number $>3 .<$ number $>$ Tim Althoff, Ryen W White, and Eric Horvitz. 2016. Influence of pokémon go on physical activity: Study and implications. Journal of Medical Internet Research 18, 12: e315.</bib $>$

$<$ bib id="bib4" $><$ number $>4 .<$ /number $>$ Peter Aspinall, Panagiotis Mavros, Richard Coyne, and Jenny Roe. 2015. The urban brain: Analysing outdoor physical activity with mobile EEG. British Journal of Sports Medicine 49, 4: 272-276.</bib>

$<$ bib id="bib5" $><$ number $>5 .<$ number $>$ Senem Kursun Bahadir, Vladan Koncar, and Fatma Kalaoglu. 2012. Wearable obstacle detection system fully integrated to textile structures for visually impaired people. Sensors and Actuators A: Physical 179: 297-311.</bib>

$<$ bib id="bib6" $><$ number $>6 .<$ /number $>$ Maryam Bandukda, Aneesha Singh, Nadia Berthouze, and Catherine Holloway. 2019. Understanding Experiences of Blind Individuals in Outdoor Nature. Extended Abstracts of the 2019 CHI Conference on Human Factors in Computing Systems - CHI EA '19, ACM Press, 1-6.</bib >

$<$ bib id="bib7" ><number >7. </number >Giulia Barbareschi, Catherine Holloway, Katherine Arnold, et al. 2020. The Social Network: How People with Visual Impairment use Mobile Phones in Kibera, Kenya. Proceedings of the 2020 CHI Conference on Human Factors in Computing Systems, Association for Computing Machinery, 1-15.</bib> $<$ bib id="bib8" $><$ number $>8$. $<$ /number $>$ Philip J Barnard, Fionnuala C Murphy, Maria Teresa Carthery-Goulart, Cristina Ramponi, and Linda Clare. Exploring the basis and boundary conditions of SenseCam-facilitated recollection.. $<$ bib $>$

$<$ bib id="bib9" $><$ number $>9$. $<$ /number $>$ Sarah L. Bell, Cassandra Phoenix, Rebecca Lovell, and Benedict W. Wheeler. 2015. Seeking everyday wellbeing: The coast as a therapeutic landscape. Social Science and Medicine 142: 56-67.</bib>

$<$ bib id="bib10" $><$ number $>10 .</$ number $>$ Cynthia L Bennett, Erin Brady, and Stacy M Branham. 2018. Interdependence as a frame for assistive technology research and design. ASSETS 2018 - Proceedings of the 20th International ACM SIGACCESS Conference on Computers and Accessibility, 161-173.</bib>

$<$ bib id="bib11" $><$ number $>11 .<$ /number $>$ Cynthia L Bennett, Jane E, Martez E Mott, Edward Cutrell, and Meredith Ringel Morris. 2018. How Teens with Visual Impairments Take, Edit, and Share Photos on Social Media. Proceedings of the 2018 CHI Conference on Human Factors in Computing Systems - CHI '18, 1-12.</bib> $<$ bib id="bib12" $><$ number $>12 .</$ number $>$ Johann Borenstein and Iwan Ulrich. The GuideCane-a computerized travel aid for the active guidance of blind pedestrians. Proceedings of International Conference on Robotics and Automation, 1283-1288.</bib >

$<$ bib id="bib13" ><number $>13 .</$ number $>$ Stacy M. Branham and Shaun K. Kane. 2015. Collaborative Accessibility: How Blind and Sighted Companions Co-Create Accessible Home Spaces. Conference on Human Factors in Computing Systems - Proceedings 2015-April: 2373-2382.</bib >

$<$ bib id="bib14" $><$ number $>14 .<$ number $>$ Kate Caldwell. 2014. Dyadic interviewing: A technique valuing interdependence in interviews with individuals with intellectual disabilities. Qualitative Research 14, 4: 488-507.</bib>

$<$ bib id="bib15" ><number >15. </number >Megan Campbell, Cynthia Bennett, Caitlin Bonnar, and Alan Borning. 2014. Where's My Bus Stop? Supporting Independence of Blind Transit Riders with StopInfo Categories and Subject Descriptors. ASSETS '14 Proceedings of the 16th international ACM SIGACCESS conference on Computers \& accessibility: $11-18 .</$ bib $>$

$<$ bib id="bib16" $><$ number $>16 .<$ number $>$ Keith William John Cheverst, Ian Norman Gregory, and Helen Turner. 2016. Encouraging Visitor Engagement and Reflection with the Landscape of the English Lake District: Exploring the potential of Locative Media.. $<$ /bib $>$

$<$ bib id="bib17" $><$ number $>17 .<$ /number $>$ Hee Chung Chung, Namho Chung, and Sung Byung Yang. 2017. An impact of tourism experience on the quality of life: The roles of autobiographical memory and SNS. ACM International Conference Proceeding Series, Association for Computing Machinery, 1-7.</bib >

$<$ bib id="bib18" $><$ number $>18 .</$ number $>$ Victoria. Clarke and Virginia. Braun. 2013. Successful qualitative research: a practical guide for beginners. SAGE. $<$ /bib $>$

$<$ bib id="bib19" $><$ number $>19 .<$ /number $>$ Marion Clawson and Jack Knetsch. 1963. Outdoor recreation research: Some concepts and suggested areas of study. Natural Resources

Journal: $250-275 .<$ /bib $>$

$<$ bib id="bib20" $><$ number $>20 .<$ number $>$ Betsy A Cuthrell. 2013. The relationship between recreational activity participation and vision related quality of life among adults with visual impairment. ProQuest Dissertations and Theses. Retrieved July 27, 2018 from

http://thescholarship.ecu.edu/bitstream/handle/10342/4321/Cuthrell_ecu_0600M_11109.pdf?sequence=1\&isAllowed=y\%0Ahttp://search.proquest.com.libe2.lib.ttu.edu/docview/1501429810?accountid=7098. $<$ /bib $>$

$<$ bib id="bib21" $><$ number $>21 .<$ number $>$ Aiden R. Doherty, Katalin Pauly-Takacs, Niamh Caprani, et al. 2012. Experiences of aiding autobiographical memory using the sensecam. Human-Computer Interaction 27, 1-2: 151-174.</bib>

$<$ bib id="bib22" $><$ number $>22 .<$ /number $>$ J Faria, S Lopes, H Fernandes, P. Martins, and J. Barroso. 2010. Electronic white cane for blind people navigation assistance. World Automation Congress (WAC), 2010: 1-7.</bib>

$<$ bib id="bib23" ><number >23. </number >Hugo Fernandes, Jose Faria, Paulo Martins, Hugo Paredes, and João Barroso. 2013. RFID mesh network as an infrastructure for location based services for the blind. 15th International Conference on Human-Computer Interaction, HCI International 20138008 LNCS, PART 5: 39-45.</bib>

$<$ bib id="bib24" ><number $>24 .<$ /number $>$ Cole Gleason, Alexander J Fiannaca, Meredith Ringel Morris, Melanie Kneisel, and Edward Cutrell. 2018. FootNotes: Geo-referenced Audio Annotations for Nonvisual Exploration. Proc. ACM Interact. Mob. Wearable Ubiquitous Technol 2, 109: 24.</bib>

$<$ bib id="bib25" ><number >25. </number >S. N Griffin-Shirley, N., Banda, D. R., Ajuwon, P. M., Cheon, J., Lee, J., Park, H. R., \& Lyngdoh. 2017. A Survey on the Use of Mobile Applications for People Who Are Visually Impaired. Journal of Visual Impairment \& Blindness 111, 4: 307-323.</bib>

$<$ bib id="bib26" ><number $>26$. < /number $>$ João Guerreiro, Dragan Ahmetovic, Daisuke Sato, Kris Kitani, and Chieko Asakawa. 2019. Airport accessibility and navigation assistance for people with visual impairments. Conference on Human Factors in Computing Systems - Proceedings, ACM. $<$ /bib $>$

$<$ bib id="bib27" ><number $>27$. </number $>$ Simon N.B. Gunkel. 2019. Multi-user (social) virtual reality commnunication.26th IEEE Conference on Virtual Reality and 3D User Interfaces, VR 2019 - Proceedings, Institute of Electrical and Electronics Engineers Inc., 1359-1360.</bib >

$<$ bib id $="$ bib28" $><$ number $>28 .</$ number $>$ Jonna Häkkilä, Nicola J. Bidwell, Keith Cheverst, et al. 2018. Reflections on the NatureCHI Workshop Series. International Journal of Mobile Human Computer Interaction 10, 3: 1-9.</bib $>$

$<$ bib id="bib29" ><number >29. </number >Jonna Häkkilä, Ashley Colley, Matilda Kalving, and Meri Tuulia Forsman. 2020. Exploring pervasive displays for cemeteries and memorial sites. Personal and Ubiquitous Computing. $</$ bib $>$

$<$ bib id="bib30" $><$ number $>30 .<$ /number $>$ Jonna Häkkilä, Petri Hannula, Elina Luiro, et al. 2019. Visiting a virtual graveyard - Designing virtual reality cultural heritage experiences. ACM International Conference Proceeding Series, Association for Computing Machinery. $</$ bib $>$

$<$ bib id="bib31" ><number >31. </number >William E. Hammitt. 1980. Outdoor Recreation: Is It A Multi-Phase Experience? Journal of Leisure Research 12, 2: 107-115.</bib> $<$ bib id="bib32" $><$ number $>32 .<$ /number $>$ Susumu Harada, Daisuke Sato, Dustin W. Adams, Sri Kurniawan, Hironobu Takagi, and Chieko Asakawa. 2013. Accessible photo album. Proceedings of the SIGCHI Conference on Human Factors in Computing Systems - CHI '13, ACM Press, 2127.</bib>

$<$ bib id="bib33" ><number $>33 .<$ number $>$ Sabrina Hauser, Ron Wakkary, and Carman Neustaedter. 2014. Understanding guide dog team interactions: Design opportunities to support work and play. Proceedings of the Conference on Designing Interactive Systems: Processes, Practices, Methods, and Techniques, DIS, 295-304.</bib>

$<$ bib id="bib34" $><$ number $>34$. $<$ /number $>$ Jemma L. Hawkins, Kathryn J. Thirlaway, Karianne Backx, and Deborah A. Clayton. 2011. Allotment gardening and other leisure activities for stress reduction and healthy aging. HortTechnology.</bib $>$

$<$ bib id="bib35" ><number $>35 .<$ /number $>$ Sara Heitlinger, N. Bryan-Kinns, Rob Comber, Bryan-Kinns Nick, and Rob Comber. 2018. Connected seeds and sensors: Co-designing internet of things for sustainable smart cities with urban food-growing communities. Proceedings of the 15th Participatory Design Conference: Short Papers, Situated Actions, Workshops and Tutorial. $</$ bib $>$

$<$ bib id="bib36" $><$ number $>36 .<$ /number $>$ Sara Heitlinger, Nick Bryan-Kinns, and Janis Jefferies. 2014. The talking plants. Proceedings of the extended abstracts of the 32nd annual ACM conference on Human factors in computing systems - CHI EA '14, 459-462.</bib>

$<$ bib id="bib37" $><$ number $>37 .<$ number $>$ Leona Holloway, Kim Marriott, Matthew Butler, and Samuel Reinders. 2019. 3D Printed Maps and Icons for Inclusion. The 21st International ACM SIGACCESS Conference on Computers and Accessibility - ASSETS '19, ACM Press, 183-195.</bib>

$<$ bib id="bib38" ><number $>38 .<$ /number $>$ Wendy Hultsman. 1998. The Multi-day, Competitive Leisure Event: Examining Satisfaction Over Time. Journal of Leisure Research 30, 4: $472-497 .</$ bib $>$

$<$ bib id="bib39" ><number $>39$. </number >Chandrika Jayant, Hanjie Ji, Samuel White, and Jeffrey P. Bigham. 2011. Supporting blind photography. The proceedings of the 13th international ACM SIGACCESS conference on Computers and accessibility - ASSETS '11, ACM Press, 203.</bib>

$<$ bib id="bib40" >< number $>40 .<$ /number $>$ Michael D Jones, Zann Anderson, Jonna Häkkilä, Keith Cheverst, and Florian Daiber. 2018. HCI Outdoors: Understanding HumanComputer Interaction in Outdoor Recreation. Extended Abstracts of the 2018 CHI Conference on Human Factors in Computing Systems - CHI '18, 1-8.</bib> $<$ bib id="bib41" $><$ number $>41$. $<$ /number $>$ Juhee Kang, Aikaterini Manthiou, Insin Kim, and Sunghyup Sean Hyun. 2016. Recollection of the Sea Cruise: The Role of Cruise Photos and Other Passengers on the Ship. Journal of Travel \& Tourism Marketing 33, 9: 1286-1308.</bib>

$<$ bib id="bib42" $><$ number $>42 .<$ number $>$ Matej Kaninsky, Sarah Gallacher, and Yvonne Rogers. 2018. Confronting people's fears about bats: Combining multimodal and environmentally sensed data to promote curiosity and discovery. DIS 2018 - Proceedings of the 2018 Designing Interactive Systems Conference, ACM Press, 931-944.</bib> 
$<$ bib id="bib43" ><number $>43 .<$ /number $>$ Stephen Kaplan. 1995. The restorative benefits of nature: Toward an integrative framework. Journal of Environmental Psychology 15, 3: $169-182 .</$ bib $>$

$<$ bib id="bib44" ><number >44. </number>Izaz Khan, Shah Khusro, and Irfan Ullah. 2018. Technology-assisted white cane: evaluation and future directions. PeerJ6: e6058.</bib> $<$ bib id="bib45" ><number $>45$. </number $>$ Jee Eun Kim, Masahiro Bessho, Shinsuke Kobayashi, Noboru Koshizuka, and Ken Sakamura. 2016. Navigating visually impaired travelers in a large train station using smartphone and Bluetooth Low Energy. Proceedings of the ACM Symposium on Applied Computing, Association for Computing Machinery, 604-611.</bib>

$<$ bib id="bib46" ><number $>46 .</$ number $>$ B Klasky and G Longley. 2015. Nature Passport..</bib >

$<$ bib id="bib47" $><$ number $>47 .<$ number $>$ Nicola T. Lautenschlager, Kay L. Cox, Leon Flicker, et al. 2008. Effect of Physical Activity on Cognitive Function in Older Adults at Risk for Alzheimer Disease. JAMA 300, 9: 1027.</bib>

$<$ bib id="bib48" ><number $>48$. < / number $>$ Bongkoo Lee and C. Scott Shafer. 2002. The Dynamic Nature of Leisure Experience: An Application of Affect Control Theory. Journal of Leisure Research 34, 3: 290-310.</bib>

$<$ bib id="bib49" $><$ number $>49$. $<$ /number $>$ Apostolos Meliones and Demetrios Sampson. 2017. Indoor blind navigator: A use case for self-guided tours in museums. ACM International Conference Proceeding Series, Association for Computing Machinery, $17-20 .</ \mathrm{bib}>$

$<$ bib id="bib50" $><$ number $>50$. $<$ /number $>$ Mei Miao, Limin Zeng, and Gerhard Weber. 2017. Externalizing cognitive maps via map reconstruction and verbal description. Universal Access in the Information Society 16, 3: 667-680.</bib $>$

$<$ bib id="bib51" $><$ number $>51 .</$ number $>$ Mia Mingus. 2010. Interdependency (exerpts from several talks) | Leaving Evidence. Retrieved May 7, 2020 from

https://leavingevidence.wordpress.com/2010/01/22/interdependency-exerpts-from-several-talks/.</bib $>$

$<$ bib id="bib52" $><$ number $>52 .<$ number $>$ David L. Morgan, Jutta Ataie, Paula Carder, and Kim Hoffman. 2013. Introducing dyadic interviews as a method for collecting qualitative data. Qualitative Health Research 23, 9: 1276-1284.</bib>

$<$ bib id="bib53"><number $>53$. < /number $>$ Evangelos Niforatos, Veranika Lim, Christian Vuerich, Marc Langheinrich, and Agon Bexheti. 2015. PulseCam: Biophysically driven life logging. MobileHCI 2015 - Proceedings of the 17th International Conference on Human-Computer Interaction with Mobile Devices and Services Adjunct, Association for Computing Machinery, Inc, 1002-1009.</bib>

$<$ bib id="bib54"><number $>54$. < /number $>$ Kenton O’Hara. 2008. Understanding geocaching practices and motivations. Conference on Human Factors in Computing Systems Proceedings, $1177-1186 .</ \mathrm{bib}>$

$<$ bib id="bib55" $><$ number $>55 .<$ /number $>$ Yutaro Ohashi and Makoto Arisawa. 2006. Nature talk: A proposed audible database system for environmental learning. Proceeding of the 2006 Conference on Interaction Design and Children, IDC '06, 167-168.</bib $>$

$<$ bib id="bib56" >< number $>56 .<$ /number $>$ Yutaro Ohashi, Hideaki Ogawa, and Makoto Arisawa. 2008. Making new learning environment in zoo by adopting mobile devices. Proceedings of the 10th international conference on Human computer interaction with mobile devices and services - MobileHCI'08, ACM Press, 489.</bib >

$<$ bib id="bib57" ><number $>57$. </number $>$ Janne Paavilainen, Hannu Korhonen, Kati Alha, Jaakko Stenros, Elina Koskinen, and Frans Mäyrä. 2017. The Pokémon go experience: A location-based augmented reality mobile game goes mainstream. Conference on Human Factors in Computing Systems - Proceedings.</bib $>$

$<$ bib id="bib58"><number >58. </number >Sabrina A. Panëels, Dylan Varenne, Jeffrey R. Blum, and Jeremy R. Cooperstock. 2013. The Walking Straight Mobile Application:

Helping the Visually Impaired Avoid Veering. Proceedings of the 19th International Conference on Auditory Display (ICAD2013), 25-32.</bib>

$<$ bib id="bib59" $><$ number $>59$. $<$ /number $>$ Mounir G. Ragheb and Charles A. Griffith. 1982. The Contribution of Leisure Participation and Leisure Satisfaction to Life Satisfaction of Older Persons. Journal of Leisure Research 14, 4: 295-306.</bib>

$<$ bib id="bib60" $><$ number $>60 .</$ number $>$ Y. Rogers, D. Stanton, M. Thompson, et al. 2004. Ambient wood. Proceeding of the 2004 conference on Interaction design and children building a community - IDC' 04 , ACM Press, 3-10.</bib>

$<$ bib id="bib61" $><$ number $>61 .</$ number $>$ Jonathan Rowell and Simon Ungar. 2003. The world of touch: An international survey of tactile maps. Part 1: Production. British Journal of Visual Impairment 21, 3: 98-104.</bib>

$<$ bib id="bib62" $><$ number $>62 .</$ number $>$ Jonathan Rowell and Simon Ungar. 2003. The World of Touch: Results of an International Survey of Tactile Maps and Symbols. The Cartographic Journal 40, 3: 259-263.</bib>

$<$ bib id="bib63" ><number $>63$. </number $>$ Manaswi Saha, Michael Saugstad, Hanuma Teja Maddali, et al. 2019. Project Sidewalk: A Web-based Crowdsourcing Tool for Collecting Sidewalk Accessibility Data at Scale. Conference on Human Factors in Computing Systems - Proceedings, Association for Computing Machinery, 1-14.</bib> $<$ bib id="bib64" $><$ number $>64 .</$ number $>$ Shraga Shoval, Johann Borenstein, and Yoram Koren. 1998. The NavBelt - A computerized travel aid for the blind based on mobile robotics technology. IEEE Transactions on Biomedical Engineering. $</ \mathrm{bib}>$

$<$ bib id="bib65" ><number $>65 .<$ /number $>$ Kin Wai Michael Siu. 2013. Accessible park environments and facilities for the visually impaired. Facilities $31,590-609$. Retrieved July 20, 2018 from http://www.emeraldinsight.com/doi/10.1108/f-10-2011-0079.</bib >

$<$ bib id="bib66" $><$ number $>66 .<$ number $>$ Kin Wai Michael Siu. 2013. Accessible park environments and facilities for the visually impaired . Emerald Group Publishing. $</$ bib $>$ $<$ bib id="bib67" $><$ number $>67 .</$ number $>$ Roddy Slorach. 2014. Disability politics and theory. Disability \& Society 29, 2: 340-341.</bib $>$

$<$ bib id="bib68" $><$ number $>68 .<$ /number $>$ Kiley Sobel, Arpita Bhattacharya, Alexis Hiniker, Jin Ha Lee, Julie A Kientz, and Jason C Yip. 2017. It wasn't really about the Pokémon: Parents' Perspectives on a Location-Based Mobile Game. Proceedings of the 2017 CHI Conference on Human Factors in Computing Systems - CHI '17, 1483-1496.</bib> $<$ bib id="bib69" ><number $>69 .<$ number $>$ Alessandro Soro, Margot Brereton, Tshering Dema, et al. 2018. The Ambient Birdhouse: An IoT device to Discover Birds and Engage with Nature..</bib $>$

$<$ bib id="bib70" $><$ number $>70 .<$ number $>$ William P Stewart. 1998. Leisure as multiphase experiences: Challenging traditions.. $<$ bib $>$

$<$ bib id="bib71"><number >71. </number>Brian L. Sullivan, Christopher L. Wood, Marshall J. Iliff, Rick E. Bonney, Daniel Fink, and Steve Kelling. 2009. eBird: A citizen-based bird observation network in the biological sciences. Biological Conservation 142, 10: 2282-2292.</bib >

$<$ bib id="bib72" ><number $>72$. </number $>$ Anja Thieme, Cynthia L. Bennett, Cecily Morrison, Edward Cutrell, and Alex S. Taylor. 2018. "I can do everything but see!" - How People with Vision Impairments Negotiate their Abilities in Social Contexts. Chi '18: 1-14.</bib>

$<$ bib id="bib73" $><$ number $>73 .<$ /number $>$ Marynel Vázquez and Aaron Steinfeld. 2012. Helping visually impaired users properly aim a camera. ASSETS'12 - Proceedings of the 14th International ACM SIGACCESS Conference on Computers and Accessibility, 95-102.</bib>

$<$ bib id="bib74" ><number $>74 .</$ number $>$ Violeta Voykinska, Shiri Azenkot, Shaomei Wu, and Gilly Leshed. 2016. How blind people interact with visual content on social networking services. Proceedings of the ACM Conference on Computer Supported Cooperative Work, CSCW, 1584-1595.</bib $>$

$<$ bib id="bib75" $><$ number $>75 .<$ number $>$ Violeta Voykinska, Shiri Azenkot, Shaomei Wu, and Gilly Leshed. 2016. How blind people interact with visual content on social networking services. Proceedings of the ACM Conference on Computer Supported Cooperative Work, CSCW.</bib>

$<$ bib id="bib76" $><$ number $>76$. </number $>$ Samuel White, Hanjie Ji, and Jeffrey P. Bigham. 2010. EasySnap: Real-time audio feedback for blind photography. UIST 2010 - 23rd ACM Symposium on User Interface Software and Technology, Adjunct Proceedings, $409-410 .</ \mathrm{bib}>$

$<$ bib id="bib77" $><$ number $>77 .<$ /number $>$ Andrea Wiggins. 2011. eBirding: Technology adoption and the transformation of leisure into science. ACM International Conference Proceeding Series, ACM Press, 798-799.</bib>

$<$ bib id="bib78" ><number $>78 .<$ /number $>$ Michele A. Williams, Amy Hurst, and Shaun K. Kane. 2013. "Pray before you step out," Proceedings of the 15th International ACM SIGACCESS Conference on Computers and Accessibility - ASSETS '13, ACM Press, 1-8.</bib>

$<$ bib id="bib79" $><$ number $>79$. </number $>$ Jacob O. Wobbrock, Shaun K. Kane, Krzysztof Z. Gajos, Susumu Harada, and Jon Froehlich. 2011. Ability-based design: Concept, principles and examples. ACM Transactions on Accessible Computing 3, 3.</bib $>$

$<$ bib id $="$ bib80" $><$ number $>80 .<$ /number $>$ Chris Wood, Brian Sullivan, Marshall Iliff, Daniel Fink, and Steve Kelling. 2011. eBird: Engaging Birders in Science and Conservation. PLoS Biology 9, 12: e1001220.</bib $>$

$<$ bib id="bib81" $><$ number $>81 .</$ number $>$ Lisa Wood, Paula Hooper, Sarah Foster, and Fiona Bull. 2017. Public green spaces and positive mental health - investigating the relationship between access, quantity and types of parks and mental wellbeing. Health and Place 48: 63-71.</bib>

$<$ bib id="bib82" $><$ number $>82 .<$ number $>$ Jian Xu, Syed Masum Billah, Roy Shilkrot, Aruna Balasubramanian, and Roy Shilkrot. 2019. DarkReader: Bridging the gap between perception and reality of power consumption in smartphones for blind users. ASSETS 2019 - 21st International ACM SIGACCESS Conference on Computers and Accessibility, ACM Press, $96-104 .</$ bib $>$

$<$ bib id="bib83" $><$ number $>83 .<$ /number $>$ Ilbin Yoon. 2017. A new approach to an inclusive urban park for all people : specially designed for visually impaired people. Retrieved from https://www.researchgate.net/publication/322146871.</bib $>$

$<$ bib id="bib84" ><number >84. </number $>$ Limin Zeng. 2015. A survey: Outdoor mobility experiences by the visually impaired. Mensch und Computer 2015 - Workshop, 391398. $<$ /bib $>$

$<$ bib id="bib85" ><number $>85$. </number $>$ Does the digital age spell the end of Braille? | The Independent. Retrieved May 4, 2020 from https://www.independent.co.uk/lifestyle/gadgets-and-tech/news/does-the-digital-age-spell-the-end-of-braille-9405836.html.</bib> 
<bib id="bib86" ><number $>86 .<$ number $>$ Popularity of audio technology is a factor in decline of braille: experts | National Observer. Retrieved May 4, 2020 from https://www.nationalobserver.com/2019/06/02/news/popularity-audio-technology-factor-decline-braille-experts. $<$ /bib $>$

$<$ bib id="bib87" $><$ number $>87 .<$ number $>$ Braille Isn't "Embattled"-We're on the Cusp of a Golden Age for Blind People. Retrieved May 4, 2020 from

https:/www.nfb.org/sites/www.nfb.org/files/images/nfb/publications/bm/bm14/bm1407/bm140709.htm.</bib> 